nghiên cứu tại Đài Loan là năm nguyên nhân hàng đầu làm nhập viện thường xuyên trong bệnh Alzheimer là hội chứng lú lẫn cấp, tai biến mạch não mới, viêm phổi, gãy xương và nhiễm khuẩn tiết niệu [5]. Bệnh nhân vào viện chủ yếu là giai đoạn nặng và trung bình,cũng phù hợp với một số nghiên cứu khác trên thế giới.

Theo phân loai tình trang dinh dưỡng của Tổ chức $Y$ tế thế giới, tỷ lệ nhóm $B M I<18,5$ chiếm tỷ lệ $45 \%$ và nhóm $B M I \geq 25$ chiếm tỷ lệ $5 \%$. Như vậy nghiên cứu cho thây $45 \%$ người bệnh thiếu năng lượng trường diễn. Tỷ lệ thiếu năng lượng trường diễn trong nghiên cứu này cao ( $45 \%$ so với $21,5 \%$ ) trong khi tỷ lệ người bệnh có $B M I \geq$ 25 thấp hơn (5\% so với 14,6\%) nghiên cứu của Vũ Thị Thu Hà tiến hành trên 288 bệnh nhân điều trị nội trú ở tất cả các khoa tại bệnh viện Lão khoa Trung ương năm 2016 với độ tuổi trung bình 77,1 tuổi [6] và cao hơn nghiên cứu của Nguyễn Thanh Bình trên đối tượng bệnh nhân SSTT khám ngoại trú tại bệnh viện, với tỷ lệ SDD là $32,2 \%$ $(n=99)$. Tỷ lệ trong nghiên cứu này cũng cao hơn kết quả của nghiên cứu được tiến hành trên 120 bệnh nhân $\geq 60$ tuổi ở Bệnh viện Phục hồi chức nằng ở Hong Kong năm 2005 (16,7\%) [2].

Tỷ lệ suy dinh dưỡng đánh giá theo công cụ MNA là $66, \%$, nguy cơ SDDlà $29,0 \%$ và chỉ có $5 \%$ là bình thường. Tỷ lệ SDD theo phương pháp MNA của nghiên cứu này cao hơn so với trong nghiên cứu của Vũ Thị Thu Hà tại Bệnh viện Lão khoa trên người bệnh nội trú các chuyên khoa $(66,0$ so với $43,4 \%)$ trong nghiên cứu của chúng tôi là bệnh nhân SSTT, tuối cao hơn, với $84 \%$ SSTT giai đoạn nặng, có rối loạn nuốt hoặc mất răng, nhai kém nển khẩu phần ăn giảm từ trước khi vào viện[6]. Tỉ lệ này của chúng tôi cao hơn các nghiên cứu khác trên thế giới có thể do đối tượng nghiên cứu của chúng tôi là bệnh nhân SSTT nặng và nằm điều trị tại bệnh viện tuyến cuối với nguyên nhân phổ biến nhất là nhiễm trùng. Đánh giá tình trạng dinh dưỡng bằng phương pháp MNA, do các nhà lão khoa quốc tế đưa ra, được xem là tin cậy, được các hiệp hội chuyên ngành dinh dưỡng khuyến nghị sử dụng cho người cao tuổi. Đây là một công cụ xác định người bệnh cao tuổi bị suy dinh dưỡng hoặc có nguy cơ suy dinh dưỡng để đưa ra các can thiệp dinh dưỡng. Những người được sàng lọc bị SDD hoặc có nguy cơ SDD có liên quan đến tỷ lệ mắc bệnh và tỷ lệ tử vong. Công cụ này có giá trị được sử dụng trong bệnh viện, nhà dưỡng lão, tại cộng đồng. MNA xác định SDD hoặc nguy cơ SDD dựa vào các tiêu chí như sụt cân, giảm khẩu phần ăn, chỉ số BMI thấp, có SSTT, khả năng đi lại. Với người bệnh SSTT thường gặp các vấn đề giảm khẩu phần ăn do các vấn đề hạn chế chăm sóc, giảm khả năng chuẩn bị thực phẩm, tự ăn uống, rối loạn nuốt. Nguyên nhân gây giảm khẩu phần ăn có thể do bản thân bệnh SSTT giảm khả năng ăn uống, bệnh lý cấp tính, bệnh mắc kèm làm bệnh nhân giảm cảm giác ngon miệng và cũng có thể do điêu kiện chăm sóc khi nằm viện không được như lúc ở nhà, các món ăn khi nằm viện không phù hợp với khẩu vị của bệnh nhân nển nguy cơ bị SDD sẽ cao hơn khi bệnh nhân nằm điêu trị nôi trú.

Tỉ lệ SDD trong nhóm bệnh nhân SSTT giai đoạn nặng cao hơn các giai đoạn khác có ý nghĩa thống kê theo cả cách đánh giá dinh dưỡng bằng công $c u ̣$ MNA và theo tiêu chuẩn GLIM. Nghiên cứu của chúng tôi cũng phù hợp với nghiên cứu khác trên thế giới cho rằng tình trạng dinh dưỡng càng xấu đi khi sa sút trí tuệ ở giai đoạncàng nặng. Trong nghiên cứu của chúng tổi tỉ lệ SDD ở nhóm có rối loạn nuốt cao hơn nhóm khổng. SDD có ở 50,9\% bểnh nhân có rối loạn nuốt [8] trong nghiên cứu của chúng tôi có tỉ lệ SDD cao hơn có thể là do trong nghiên cứu của chúng tôi tỷ lệ bệnh nhân SSTT giai đoạn nặng chiếm tỉ lệ cao hớn nên bệnh nhân bị rối loạn nuốt có tî lệ nhiều hơn. Kết quả nghiên cứu của chúng tôi bệnh nhân có rối loạn nuốt chiếm tỉ lệ cao hơn của Nguyễn Thanh Bình năm 2018 (77,4\% so với $18,2 \%)$,

Như vậy trong nghiên cứu của chúng tôi đánh giá dinh dưỡng theo công cụ MNA và tiêu chuẩn GLIM đều có tỉ lệ SDD cao. Đánh giá tình trạng dinh dưỡng theo BMI là tiêu chuẩn của Tổ chức y tế thế giới dành cho người $>18$ tuổi, nhưng với đối tượng người cao tuổi theo khuyến cáo của các nhà lão khoa quốc tế nên sử dụng phương pháp sàng loc dinh dưỡng MNA để sàng loc SDD và nguy cơ SDD từ giai đoạn chưa có giảm cân nhằm phát hiện sớm và có kế hoạch can thiệp kịp thời. Tiêu chuẩn GLIM là công cụ chẩn đoán SDD mới nhất mà các hiệp hội dinh dưỡng lâm sàng trên thế giới đã đồng thuận, trong nghiên cứu của chúng tôi cho thấy tỉ lệ SDD khi đánh giá theo GLIM cũng cao gần tướng đương công cụ MNA. Theo khuyến cáo của hội dinh dưỡng lâm sàng châu Âu và hiệp hội Alzheimer đưa ra để làm giảm tỉ lệ SDD, tất cả các BN SSTT cần được sàng lọc, theo dõi và đánh giá tình trạng dinh dưỡng định kỳ, bệnh nhân và người chăm sóc cần được giáo dục dinh dưỡng và tư vấn dinh dưỡng đặc biệt về sụt cân, hành vi ăn uống. SDD là hiện tượng nghiêm trọng, đối với người có nguy cở cần được đánh giá chi tiết về chế độ 
ăn, hành vi ăn uống, nhu cầu hỗ trợ cho ăn, cân can thiệp ngay, và tích cực để phục hồi SDD.

\section{KẾT LUẬN}

Người bệnh sa sút trí tuệ điều trị nội trú có tỉ lệ suy dinh dưỡng cao. Có mốiliên quan giữa tình trạng dinh dưỡng của người bệnh với các yếu tố tuổi, giai đoạn SSTT, rối loạn nuốt. Do vậy, cần quan tâm đánh giá dinh dưỡng và can thiệp dinh dưỡng sớm đối với bệnh nhân SSTT.

\section{TÀI LIỆU THAM KHẢO}

1. Guerchet, M., M. Prince, and M. Prina, Numbers of people with dementia worldwide: An update to the estimates in the World Alzheimer Report 2015. 2020.

2. Miao, J.-P., et al., Comparison of two malnutrition risk screening tools with nutritional biochemical parameters, BMI and length of stay in Chinese geriatric inpatients: a multicenter, crosssectional study. BMJ open, 2019. 9(2): p. e022993.

3. Nguyê̂n Thanh Bình, Đặc điểm lấm sàng và gánh nặng ngươi chăm sóc cho bệnh nhân
Alzheimer giai đoạn nă̆ng, in Luận án Tiến sỹ $Y$ hoc. 2018, Trường Đại học Y Ha Noi: Ha Noi.

4. Shua-Haim, J.R., et al., Depression among Alzheimer's caregivers: Identifying risk factors. American Journal of Alzheimer's Disease \& Other Dementias $\AA$, 2001. 16(6): p. 353-359.

5. Lin, P.-C., et al., Primary diagnoses and outcomes of emergency department visits in older people with dementia: a hospital-based retrospective study in Taiwan. International psychogeriatrics, 2020. 32(1): p. 97-104.

6. Vũ Thị Thu Hà, Tình trạng dinh dưỡng, thói quen ăn uống và khâu phân ăn của bệnh nhân người cao tuối tại Bệnh viện Lão khoa Trung Ương năm 2016, in Khoá luận tốt nghiệp cử nhân Y khoa chuyên ngành dinh dưỡng. 2017, Đại học Y: Hà Nội.

7. Tombini, M., et al., Nutritional status of patients with Alzheimer's disease and their caregivers. Journal of Alzheimer's Disease, 2016. 54(4): p. 1619-1627.

8. Peñalva-Arigita, A., et al., Prevalence of dysphagia in a regional hospital setting: Acute care hospital and a geriatric sociosanitary care hospital: A cross-sectional study. Clinical nutrition ESPEN, 2019. 33: p. 86-90.

\section{MộT Số CHỈ SỐ Sọ MẶT CỦA BỆNH NHÂN Có TƯƠNG QUAN XƯƠ'NG LOẠI II DO KÉM PHÁT TRIỂN XƯƠNG HÀM DƯỚI}

Trần Nguyên Giang1, Nguyễn Thị Thu Phương²

\section{TÓM TẮT}

Nghiên cứu mô tả cắt ngang được thực hiên trên 63 bệnh nhân ở Trung tâm Kĩ thuật cao của Viện Đào tạo Răng Hàm Mặt - trường Đại học Y Hà Nội và Bệnh viện Răng Hàm Mặt Trung ưởng Hà Nội. Các chỉ số nghiên cứu của bềnh nhân đo trên phim chụp sọ nghiêng từ xa kỹ thuật số được phân tích trên Stata 14.0 mô tả giá trị trung bình và kiểm định sự khác biệt giữa nam và nữ về các chỉ số sọ mặt trên phim nghiêng có tương quan xương loại II do kém phát triển xương hàm dưới. Kết quả cho thấy các chỉ số sọ mặt nghiêng của bệnh nhân: góc $A N B=6,88^{\circ} \pm 1,34$; góc $\mathrm{i} / \mathrm{NS}=39,25^{\circ} \pm 6,50$; góc $\mathrm{FMIA}=48,80^{\circ} \pm 6,09$; góc Gl'-Sn-Pg' $=167,74^{\circ} \pm 5,3$; chi số i-NB, M-Me, N-ANS có giá trị lần lượt là $7,70 \pm 1,92,112,68 \pm 8,47$ và $50,94 \pm 4.01(\mathrm{~mm})$ và tỳ lệ tầng mặt N-ANS/N-Melà 0,45 . Các chỉ số trên có sự khác biệt có ý nghĩa thống kê ở hai giới $(p<0,05)$, các chỉ số còn lại sự khác biệt không có ý nghĩa thống kê.

Tư khóa: Trục răng cửa dưới, sai khớp cắn loại II, chỉ số sọ mặt.

\footnotetext{
${ }^{1}$ Bệnh viện Trung ương Thái Nguyên

2Trường Đại hoc Y Hà Nội.

Chịu trách nhiệm chính: Trần Nguyên Giang

Email: trangiangrhm@gmail.com

Ngày nhận bài: 20/8/2021

Ngày phản biện khoa học: 9/9/2021

Ngày duyệt bài: 28/9/2021
}

\section{SUMMARY \\ SOME CRANIOFACIAL INDEXES OF PATIENTS \\ IN THE CORRELATION WITH CLASS II MALOCCLUSION BY UNDERDEVELOPMENT OF LOWER JAW BONE}

The cross-sectional study was conducted on 63 patients at the High-Technology Center of School of Odonto-Stomatology - Hanoi Medical University and Hanoi National Hospital of Odonto-Stomatology. The patient's indicators were measured on digitally tilted cranial imaging. The results were analyzed on Stata 14.0 software, the average values were calculated, and the Mann-Whitney $U$ test was used to test for statistically significant differences between men and women.The results showed that the average value of the patient's tilted cranial indicators wasANB $=6,88^{\circ}$ $\pm 1,34 ; \mathrm{i} / \mathrm{NS}=39,250^{\circ} \pm 6,50 ; \quad \mathrm{FMIA}=48,80^{\circ} \pm 6,09 ; \mathrm{Gl} \mathrm{I}^{\prime} \mathrm{Sn}$ $\mathrm{Pg}^{\prime}=167,74^{\circ} \pm 5,3$. In addition, the $\mathrm{i}-\mathrm{NB}, \mathrm{M}-\mathrm{Me}$, and N-ANS indexes are 7,70 $\pm 1,92,112,68 \pm 8,47$ and $50,94 \pm 4,01(\mathrm{~mm})$, respectively. N-ÁNS/N-Me ratio was 0,45 . All of the above indicators have statistically significant differences in the sexes $(p<0,05)$.

Keywords: Lower incisor axis, class II malocclusion, craniofacial index.

\section{I. ĐẶT VẤN ĐỀ}

Sai khớp cắn loại II là loại sai lệch khớp cắn rất hay gặp ở bệnh nhân nắn chỉnh răng với kiểu xương và răng rất đặc trưng. Có nhiêu nguyên 
nhân dẫn tới sai khớp cắn loại II, tuy nhiên theo nghiên cứu của Proffit cho thấy rằng nguyên nhân lùi xương hàm dưới là nguyên nhân hay gặp nhất ${ }^{1}$. Sai khớp cắn loại II là một trong những loại hay gặp trên lâm sàng chiếm 20,8\% theo thống kê của Bệnh viện Răng Hàm Mặt trung ương Hà Nội². Sai khớp cắn loại II, đặc biệt là nguyên nhân do xương gây ảnh hưởng lớn đến thẩm mỹ khuôn mặt, nhất là mặt nghiêng và đây cũng là lý do khiến bệnh nhân đến khám và điều trị. Dù nguyên nhân là gì, tất cả các bệnh nhân tìm kiếm điều trị nắn chỉnh răng đều mong muốn có sự cải thiện thẩm mỹ hàm răng và khuôn mặt của họ. Điều này sẽ không thể thực hiện được nếu thiếu sự hiểu biết đầy đủ về khuôn mătt trước khi điều trỉ ${ }^{3}$.

Kể từ khi ra đời, phim so mặt nghiêng từ xa đã trở thành một phương tiện hỗ trợ trong chẩn đoán và điều trị nắn chỉnh rắng với rất nhiều các phương pháp phân tích mô xương và mô mềm trên phim. Bên cạnh phim so mặt nghiêng từ xa, ảnh chụp kỹ thuật số chuẩn hóa cũng là một trong những dữ liệu lâm sàng giúp phân tích các đặc điểm thẩm mỹ mô mềm khuôn mặt không thể thiếu của các bác sỹ nắn chỉnh răng trước, trong và sau điều trị bởi nhiều ưu điểm như tính tiên lợi trong sử dụng, lưu trũ̃, trao đổi thông tin với độ tin cậy cao.

Trục răng cửa dưới có vai trò quan trọng trong chỉnh nha, phục hình và phẫu thuật chỉnh hình hàm mặt, nó liên quan đến khoảng tự do liên thân răng, góc trượt lồi cầu trong cơ chế bảo vệ của bộ răng và truyền lực nhai sinh lí cũng như thẩm mĩ của bộ răng. Tuy nhiên, có rất ít các đề tài nghiên cứu mô tả về vấn đề này, đây vẫn còn là một mảng trống cần nghiên cứu. Vì vậy chúng tôi tiến hành nghiên cứu với mục tiêu "Mô tả một số chỉ số sọ mặt trên phim sọ nghiêng có tương quan xương loại II do kém phát triển xương hàm dưới".

\section{II. ĐỐI TƯợNG VÀ PHƯƠ'NG PHÁP NGHIÊN CỨU}

2.1. Đối tượng nghiên cứu. Bệnh nhân đến khám, chụp phim tại Trung tâm Kĩ thuật cao của Viện Đào tạo Răng Hàm Mặt - Trường Đại học Y Hà Nội và Bệnh viện Răng Hàm Mặt Trung ương Hà Nội

- Tiêu chuẩn lựa chọn:Bênh nhân tuổi từ 18-25; tương quan xương loại II với góc ANB $>4^{0}$, và góc SNB $<78^{\circ}$ trên phim Cephalometric; không có dị tật bẩm sinh vùng hàm mặt; chưa từng điều trị chỉnh nha; chưa từng điều trị chỉnh hình xương vùng hàm mặt; không bị chấn thương vùng hàm mặt và có đây đủ các răng vĩnh viễn (không tính RHL thứ ba).

- Tiêu chuẩn loại trừ: Bệnh nhân có cầu chụp răng giả, mất tổ chức cứng làm giả chu vi răng.

- Thời gian và địa điểm nghiên cứu: Từ tháng 7 năm 2020 đến tháng 7 năm 2021 tại Trung tâm kỹ thuật cao Răng Hàm Mặt - Viện Đào tạo Răng Hàm Mặt - Trường Đại học $Y$ Hà Nội và Bệnh viện Răng Hàm Mặt TW Hà Nội.

\subsection{Phương pháp nghiên cứu}

- Thiết kế nghiên cứu:Mô tả cắt ngang

- Cṍ mẫu: Cõ̃ mẫu được xác định theo công thức ước tính một giá trị trung bình trong quần thể với độ tin cậy lấy ở ngưỡng sác xuất $a=5 \%$, $Z=1,96$, mức sai lệch tương đối giữa tham số mẫu và quần thể lấy bằng 0,1 . Thay các số liệu vào công thức tính được cỡ mẫu tối thiểu là $\mathrm{n}=54$ cho cả nam và nữ, thực tế trong nghiên cứu này là 63 bệnh nhân cho cả hai giới.

- Quy trình thu thập thông tin: Bệnh nhân sau khi được lựa chọn đạt theo tiêu chí sẽ được khám, phỏng vấn và được chụp phim mặt sọ nghiêng từ xa. Những phim chụp đạt yêu cầu được chuẩn hóa thước đo trên phim, tiến hành xác định các điểm mốc và đo các biến số nghiên cứu bằng phần mềm AutoCAD 2013 sau đó nhập vào máy tính.

2.3. Công cụ thu thập và xử lý số liệu: các số liệu từ phim chụp sọ mặt nghiêng từ xa kỹ thuật số của bệnh nhân được nhập vào máy tính và mã hóa sau đó được xử lý và phân tích trên phầm mềm STATA 14.0. Thống kê mô tả giá trị trung bình và Mann-Whitney $U$ test được sử dụng kiểm định sự khác biệt có ý nghĩa thống kê theo giới với $\mathrm{p}<0,05$.

2.4. Đạo đức trong nghiên cứu: Nghiên cứu này được thực hiện dưới sự đồng ý, hợp tác của các bệnh nhân tại Trung tâm kỹ thuật cao Răng Hàm Mặt- Viện Đào tạo Răng Hàm Mặt đại học Y Hà Nội, bệnh viện Răng Hàm Mặt Trung ương Hà Nội và sự đồng ý của lãnh đạo viện. Mọi thông tin thu thập được trong quá trình nghiên cứu sẽ được giữ bí mật để phục vụ nghiên cứu.

\section{KẾT QUẢ NGHIÊN CỨU}

Trong số 63 bệnh nhân tham gia nghiên cứu có 46 bệnh nhân nữ chiếm $73 \%$ và 17 bệnh nhân nam chiếm $27 \%$.

Bảng 1 mô tả các chỉ số sọ mặt trên phim sọ nghiêng của đối tượng nghiên cứu. Góc liên xương hàm trên và hàm dưới (ANB) là $6,88^{\circ}$ $\pm 1,34$ và có sự khác biệt có ý nghĩa thống kê ở hai giới $(p<0.05)$. Góc trục răng cửa hàm dưới với mặt phẳng nền sọ (i/NS) và góc trục răng 
cửa hàm dưới so với mặt phẳng Frankfort Horizonal (FIMA) có giá trị lần lượt là $39,25^{\circ} \pm$ 6,25 và $48,80^{\circ} \pm 6,09$ và giá trị hai góc này của nam lớn hơn nữ, có sự khác biệt có ý nghĩa thống kê ở hai giới $(p<0.05)$. Góc lồi mặt không qua mũi trung bình $167,74^{\circ} \pm 5,30$, độ nhô răng cửa dưới trung bình là $7,70 \mathrm{~mm} \pm 1,92$, góc và chỉ số này sự khác biệt có ý nghĩa thống kê ở hai giới $(p<0.05)$ với giá trị trung bình của nữ lớn hơn nam. Chiều cao tâng mặt trước ( $\mathrm{N}-\mathrm{Me})$ và chiều cao tầng mặt giữa (N-ANS) có giá trị trung bình lân lượt là $112,68 \mathrm{~mm} \pm 8,47$ và $50,94 \mathrm{~mm} \pm$ 4,0 , có sự khác biệt có ý nghĩa thống kê $(p<0,05)$. Tỷ lệ tầng mặt nam 0.46 cao hơn nũ 0.45 và sự khác biệt này có ý nghĩa thống kê với $\mathrm{p}=0,046$.

Bảng 1. Đặc điểm của các chi số sọ mặt trên phim sọ nghiêng của đối tượng nghiên cứu

\begin{tabular}{|c|c|c|c|c|c|c|c|}
\hline \multirow{2}{*}{ Biến số } & \multicolumn{2}{|c|}{ Nam } & \multicolumn{2}{|c|}{ Nữ } & \multicolumn{2}{|c|}{ Chung } & \multirow{2}{*}{$\mathbf{P}$} \\
\hline & TB & ĐLC & TB & ĐLC & TB & ĐLC & \\
\hline \multicolumn{8}{|c|}{ Các chỉ số nền sọ } \\
\hline $\mathrm{SN}-\mathrm{FH}\left({ }^{\circ}\right)$ & 9,20 & 4,02 & 9,92 & 2,63 & 9,73 & 3,05 & 0,957 \\
\hline $\mathrm{S}-\mathrm{Gn} / \mathrm{FH}\left({ }^{\circ}\right)$ & 62,26 & 4,48 & 62,11 & 3,32 & 62,15 & 3,63 & 0,988 \\
\hline $\mathrm{FH} / \mathrm{GoGn}\left({ }^{\circ}\right)$ & 26,57 & 7,08 & 29,44 & 5,37 & 28,67 & 5,96 & 0,109 \\
\hline $\mathrm{FH} / \mathrm{N}-\mathrm{Pg}\left({ }^{\circ}\right)$ & 85,41 & 4,08 & 85,75 & 2,94 & 85,66 & 3,25 & 0,914 \\
\hline \multicolumn{8}{|c|}{ Các chỉ số xương hàm trên và xương hàm dưới } \\
\hline SNA $\left({ }^{\circ}\right)$ & 82,65 & 1,50 & 83,35 & 1,74 & 83,16 & 1,70 & 0,157 \\
\hline SNB $\left(^{\circ}\right)$ & 76,35 & 1,17 & 76,26 & 1,66 & 76,28 & 1,53 & 0,637 \\
\hline ANB $\left(^{\circ}\right)$ & 6,31 & 1,04 & 7,09 & 1,38 & 6,88 & 1,34 & 0,023 \\
\hline \multicolumn{8}{|c|}{ Các chỉ số rằng hàm trên và răng hàm dưới } \\
\hline $\mathrm{i}-\mathrm{MP}\left({ }^{\circ}\right)$ & 101,45 & 7,01 & 102,93 & 6,82 & 102,53 & 6,85 & 0,369 \\
\hline $\mathrm{i} / \mathrm{NS}\left(^{\circ}\right)$ & 42,79 & 6,34 & 37,94 & 6,18 & 39,25 & 6,55 & 0,011 \\
\hline FMIA $\left(^{\circ}\right)$ & 51,97 & 6,69 & 47,63 & 5,48 & 48,80 & 6,09 & 0,018 \\
\hline $\mathrm{I} / \mathrm{i}\left({ }^{\circ}\right)$ & 109,97 & 10,22 & 107,58 & 8,78 & 108,22 & 9,17 & 0,239 \\
\hline \multicolumn{8}{|c|}{ Các chỉ số phần mềm } \\
\hline Cm-Sn-Ls ( $\left.{ }^{\circ}\right)$ & 92,24 & 9,46 & 91,62 & 16,40 & 91,79 & 14,78 & 0,716 \\
\hline Sn-Ls/Li-Pg' (0) & 121,62 & 18,93 & 116,02 & 14,27 & 117,53 & 15,70 & 0,183 \\
\hline $\mathrm{Gl}^{\prime}-\mathrm{Sn}-\mathrm{Pg}^{\prime}\left({ }^{\circ}\right)$ & 164,41 & 3,83 & 168,97 & 5,27 & 167,74 & 5,30 & 0,000 \\
\hline \multicolumn{8}{|c|}{ Các chỉ số độ nhô rằng cửa và chỉ số Wits } \\
\hline $\mathrm{i}-\mathrm{NB}(\mathrm{mm})$ & 6,80 & 1,83 & 8,04 & 1,86 & 7,70 & 1,92 & 0,043 \\
\hline I-NA (mm) & 5,32 & 1,36 & 5,03 & 1,64 & 5,11 & 1,57 & 0,631 \\
\hline Wits (mm) & 6,31 & 2,43 & 5,41 & 3,85 & 5,65 & 3,52 & 0,107 \\
\hline \multicolumn{8}{|c|}{ Các chỉ số độ nhô môi so với đường S } \\
\hline Ls-S (mm) & 1,93 & 1,57 & 1,80 & 1,57 & 1,84 & 1,56 & 0,828 \\
\hline Li-S (mm) & 3,29 & 3,04 & 4,28 & 2,80 & 4,01 & 2,88 & 0,210 \\
\hline \multicolumn{8}{|c|}{ Các kích thước và tỷ lệ các tâng mặt } \\
\hline $\mathrm{N}-\mathrm{Me}(\mathrm{mm})$ & 115,73 & 3,82 & 111,55 & 9,43 & 112,68 & 8,47 & 0,003 \\
\hline $\mathrm{N}-\mathrm{ANS}(\mathrm{mm})$ & 53,65 & 3,16 & 49,94 & 3,86 & 50,94 & 4,01 & 0,000 \\
\hline ANS-Me (mm) & 62,09 & 3,69 & 61,61 & 6,70 & 61,74 & 6,01 & 0,430 \\
\hline $\mathrm{N}-\mathrm{ANS} / \mathrm{N}-\mathrm{Me}(\mathrm{mm})$ & 0,46 & 0,02 & 0,45 & 0,02 & 0,45 & 0,02 & 0,046 \\
\hline
\end{tabular}

: Mann-Whitney U test, số in đậm biểu thị chogiá trị p<0,05.

\section{BÀN LUÂ̂N}

Nghiên cứu mô tả cắt ngang trên 63 bệnh nhân có tỷ lệ tham gia nghiên cứu của nữ giới gấp 2.5 lần so với nam giới, do nhu cầu thẩm mỹ của nữ giới luôn cao hơn nam giới và tâm lý từ phía gia đình và bệnh nhân quan tâm đến thẩm mỹ cho nữ nhiều hớn.

Kết quả phân tích trên phim sọ mặt nghiêng từ xa cho thấy các chỉ số xương hàm trên và xương hàm dưới của nữ lớn hơn nam kết quả này tương đồng với một số nghiên cứu trên thế giới và Việt Namvề sai lệch khớp cắn loại II theo Angel ${ }^{5,6}$. Đồng thời, sự khác biệt giữa hai giới với các chỉ số này trong các nghiên cứu đều được chỉ ra là không có sự khác biệt $(p>0.05)$. Tuy nhiên, theo các nghiển cứu của McNamara góc SNA, SNB và ANB được đo ở cả hai giới vì tâm quan trọng của chúng trong chẩn đoán chỉnh nha dùng để phân tích vị trí và định hướng không gian của các cơ sở xương hàm mă̆t ${ }^{5}$. Góc ANB trong nghiên cứu của chúng tôi có giá trị trung bình là $6,88^{\circ} \pm 1,34$ tương đồng với kết quả 
nghiên cứu về sai lệch khớp cắn loại II do lùi xương hàm dưới của Trịnh Đỗ Vân Ngà với góc $A N B=6,91^{0} \pm 1,51^{6}$ và lớn hơn nhiều so với giá trị bình thường là $3,6^{\circ} \pm 2,5$ theo nghiên cứu của Peak. Điều này có thể được lý giải như sau do góc SNA là chỉ số đánh giá tương quan giữa xương hàm trên và nền sọ, trong nghiên cứu của chúng tôi góc SNA có giá trị bình thường nhưng góc SNB lại nhỏ hơn giá trị bình thường. Đây là nguyên nhân tạo nên sự mất cân xứng theo chiều trước sau giữa xương hàm trên và xương hàm dưới được thể hiện ở góc ANB trong nghiên cứu lớn hơn giá trị bình thường rất nhiều. Mặt khác, theo Steiner thông số góc ANB có giá trị thực tế bởi vì nó đánh giá được bất thường và mức chênh lệch của xương hàm trên hoặc xương hàm dưới có được cải thiện sau can thiệp hay không.

Góc FMIA trong nghiên cứu là $48.80^{\circ}$ thấp hơn so với nghiên cứu tại Brazill có giá trị là $58.93^{\circ}{ }^{6}$ đồng thời cùng thấp hơn so với giá trị chuẩn là $68^{\circ}$. Góc FMIA là một trong ba góc Tweed, giá trị của nó thể hiện gương mặt có cân đối không và là chỉ số đánh giá bệnh nhân sau điều trị. Sự khác biệt của góc FIMA gián tiếp chứng minh rằng răng cửa dưới có độ nghiêng nhiều hơn ở sai lệch loại II khi so sánh với nhóm đối chứng ${ }^{6}$. Góc liên răng cửa là $108,22^{\circ} \pm 9,17$ tương đồng so với nghiên cứu tại Việt Nam $102,8^{\circ} \pm 9,4$ nhỏ hơn giá trị trung bìnhgóc này thấp hơn so với các nghiên cứu trước Lamberton 110,8 ; Jamilian $118,7^{8}$. Kết quả này dẫn đến mất cân bằng hai môi nặng. Ngoài ra, góc liên răng cửa có giá trị nhỏ hơn bình thường tạo nên vẻ mặt lồi đặc trưng của các bệnh nhân gây ảnh hưởng đến thẩm mĩ khuôn mặt. Vì thế chỉ số này được sử dụng rộng rãi trong rất nhiều nghiên cứunhư một tiêu chuẩn trên phim so nghiêng để chẩn đoán bệnh nhân có vẩu răng hay không và nó cũng là một chỉ số để đánh giá kết quả điều trị hữu hiệu ${ }^{8}$.

Trong các chỉ số phầm mềm có góc mũi môi (Cm-Sn-Ls) trung bình trong nghiên cứu đo được là $91,79^{\circ} \pm 14,78$, nam và nữ không có sự chênh lệch $(p>0,05)$. Kết quả tương đồng nhóm bệnh nhân người Nhật $94,83^{\circ}$ và nhọn hơn người châu Âu theo Legan- Burstone là $102^{0} 7$. Hình thái sọ mă̆t người châu Á tương đương nhau và khác so với người châu Âu có thể do nguồn gốc tổ tiên từ xa xưa. Thêm vào đó, mức độ nhọn của góc mũi môi phản ánh mức độ vẩu của răng do đó có thể thấy người Việt Nam vẩu hơn so với người châu Âu và kết quả này phù hợp với một số nghiên cứu trước đây?. Góc lồi mă̆t không qua mũi $\left(\mathrm{Gl}^{\prime}-\right.$ $\left.\mathrm{Sn}-\mathrm{Pg}^{\prime}\right)$ của nữ giới lớn hơn nam giới và có sự khác biệt có ý nghĩa thống kê ở hai giới $(p<0,05)$. Kết quả trái ngược nghiên cứu trên nhóm trẻ vi thành niên sai khớp cắn loại II tại Việt Nam cho đặc điểm mặt nam giới lồi hớn nữ giới ${ }^{8}$. Điều này có thể do tuổi vị thành niên những chỉ số về răng hàm mặt đang trong giai đoạn phát triển trong khi đối tượng nghiên cứu của chúng tôi là nhưng người đã hoàn thiện về cấu trúc sọ mặt nên dẫn đến sự khác biệt trên.

\section{KẾT LUẬN}

Những chỉ số so măt trong sai khớp cắn loai II do kém phát triển xương hàm dưới có sự khác biệt có ý nghĩa thống kê giữa nam và nữ như góc liên xương hàm trên và xương hàm dưới (ANB), góc lồi mặt không qua mũi $\left(\mathrm{Gl}^{\prime}-\mathrm{Sn}-\mathrm{Pg}^{\prime}\right)$ và tỷ lệ tầng mặt (N-ANS/N-Me), trong đó giá trị trung bình của nữ lớn hơn nam. Mặt khác, các chỉ số góc trục răng cửa dưới với mặt phẳng nền sọ (i/NS), góc trục răng cửa hàm dưới so với mặt phẳng Frankfort Horizonal (FIMA), chiều cao tầng mặt trước $(\mathrm{N}-\mathrm{Me})$ và chiều cao tầng mặt giữa (N-ANS)có giá trị trung bình của nam lớn hơn nữ và sự khác biệt có ý nghĩa thống kê.

\section{TÀI LIẸU THAM KHẢO}

1.Proffit W.R., Fields H.W., Sarver D.M. Malocclusion and Dentofacial Deformity in Contemporary Society. Contemporary Orthodontics, Fourth Edition, Mosby Elsevier, St. Louis.2007;3-23.

2. Nguyến Thi Bích Ngoc. Nhận xét và đánh giá hiệu quả lâm sàng điều trị lệch lạc khớp cắn Angle II do lùi xương hàm dưới bằng hàm chức năng. Luận văn tốt nghiêpp Bác sỹ nội trú bệnh viện, Trường Đại học Y Hà Nội. 2003; 5-41.

3. J. B. de Paiva, M. F. Attizzani, H. Miasiro Júnior, and J. Rino Neto.Facial harmony in orthodontic diagnosis and planning.Braz. Oral Res.2010;52-57.

4. Nguyễn Tuấn Anh, Tống Minh Sơn,Lê Hưng.Đăc điểm sọ mặt trên phim so-măt nghiêng của người trưởng thành có sai khớp cẳn loại II. Tapp chí Y Dược học quân sự.2017

5. Kiran Kumar Dodda, Singamsetty E. R. V. Prasad, Ravi Krishna Kanuru, et alDiagnostic features of Angle's Class II div 2 malocclusion. JISPCD. 2015;5(6): 513-517.

6. Paulo César Tukasan, Maria Beatriz Borges de Araújo Magnani, Darcy Flávio Nouer. Craniofacial analysis of the Tweed Foundation in Angle Class II, division 1 malocclusion.Brazilian Oral Research. 2005; 19(1):69-75.

7. Nguyến Thi Bích Ngoc.Nghiên cứu sự thay đổi hinh thái mố cứng, mố mềm của khuôn mặt sau điều trị chỉnh răng lệch lac khớp cắn Angle İ, vẩu xương ổ răng hai hàm có nhổ răng. Luận án tiến sỹ, Trường Đại học Y Hà Nội.2014.

8. Nguyê̂n Hùng Hiệp.Nghiên cứu một số chỉ số đầu măt ở trẻ em Viêt Nam 12 tuối để ứng dung trong điều trị y học. Luận án tiến sỹ Y học, đại học Y Hà Nội.2020. 